\title{
Optimal Machining Parameters of EDM in Gas Based on Response Surface Methodology
}

\author{
Yan-Cherng Lin*, Han-Ming Chow, Yuan-Feng Chen, Jia-Feng Liu \\ Department of Mechanical Engineering, Nan Kai University of Technology, Nantou County, Taiwan

\section{Email address:} \\ ycline@nkut.edu.tw (Yan-Cherng Lin),hmchow@nkut.edu.tw (Han-Ming Chow), yfchen@nkut.edu.tw (Yuan-Feng Chen), \\ myself0924@gmail.com (Jia-Feng Liu) \\ ${ }^{*}$ Corresponding author
}

\section{To cite this article:}

Yan-Cherng Lin, Han-Ming Chow, Yuan-Feng Chen, Jia-Feng Liu. Optimal Machining Parameters of EDM in Gas Based on Response Surface Methodology. International Journal of Materials Science and Applications. Vol. 5, No. 6, 2016, pp. 241-247.

doi: $10.11648 /$ j.ijmsa.20160506.12

Received: September 25, 2016; Accepted: October 17, 2016; Published: October 18, 2016

\begin{abstract}
This paper aims to establish an effective mathematical model with relation to electrical discharge machining (EDM) in gas based on response surface methodology (RSM). Moreover, the optimal combination levels of machining parameters for material removal rate (MRR) and surface roughness (SR) were also explored. The experimental tasks were implemented by a specific design of experimental method named central composite design (CCD) method based on RSM to develop quadratic regression mathematical model. The significant parameters and their interactions were examined by analysis of variance (ANOVA) to evaluate the importance on MRR and SR. The essential parameters of EDM in gas such as peak current $\left(\mathrm{I}_{\mathrm{p}}\right)$, pulse duration $\left(\mathrm{T}_{\mathrm{p}}\right)$, air pressure $\left(\mathrm{G}_{\mathrm{P}}\right)$ and servo reference voltage $\left(\mathrm{S}_{\mathrm{v}}\right)$ were chosen to investigate the effects on MRR and SR. From the analysis results, the optimal set of parameter setting levels were 12 A peak current $\left(\mathrm{I}_{\mathrm{p}}\right), 750 \mu$ s pulse duration $\left(\mathrm{T}_{\mathrm{p}}\right), 5 \mathrm{~kg} / \mathrm{cm}^{2}$ gas pressure $\left(\mathrm{G}_{\mathrm{P}}\right)$ and $34 \mathrm{~V}$ servo reference voltage $\left(\mathrm{S}_{\mathrm{v}}\right)$, and the optimization of MRR and SR were $1.99 \mathrm{~mm}^{3}$ and $2.43 \mu \mathrm{m}$ as the machining parameters were set at the optimal levels.
\end{abstract}

Keywords: EDM in Gas, Response Surface Methodology, Optimal Machining Parameter, Material Removal Rate, Surface Roughness

\section{Introduction}

Electrical discharge machining (EDM) is one of non-traditional machining processes that is widely employed in mold and die manufacturing industries. The machining performances of EDM process are not associated with the mechanical properties of materials, namely tensile strength, hardness, and toughness. Thus, the EDM process demonstrates vital potential and is greatly used in difficult-to-machine materials such as mold steels, ceramics, and composites $[1,2]$. In last decade, the several researchers focused on the issues of improving the machining efficiency, machining precision, quality of machined surface, and the machining stabilization in EDM process [3-6].

Generally, kerosene was adopted as the dielectric fluid in conventional EDM, and the oil-based dielectric would incur some drawbacks such as fire hazard, air pollution, and environmental damage. The idea of EDM conducted in gas media was proposed by Kuneida and his coworkers [7, 8]. The molten materials caused by electrical spark were expelled from machining gap by a high pressure of gas stream. Lin et al. [9] investigated the EDM characteristics of SKD 61 steel by using gas media as dielectric. The effects of essential input variables of the EDM in gas on machining performances were comprehensively explored. The scheme of EDM in gas media has also been manipulated to study the machining feasibility in wire electrical discharge machining (WEDM) [10, 11]. Yu et al. [12] conducted an experimental work to elucidate the capability of EDM in gas for machining tungsten carbides; their experimental results suggested that the tungsten carbides could be machined by EDM milling in gas media using uniform tiny electrodes.

According to the previous investigations, the compressed gas stream can be regarded as a practical dielectric to maintain the progress of electrical sparks consecutively in EDM process. 
However, the prediction models for selection of the suitable machining parameters for the purpose of obtaining higher efficiency and accuracy is also a challenge task due to the presence of a large number of input variables. In this paper, an attempt was implemented to model the machining performances through the response surface methodology (RSM). The material removal rate (MRR) and surface roughness (SR) were selected to evaluate the machining performances. The RSM is a collection of mathematical and statistical procedures that is useful for the modeling and the analysis of problems in which the response of demand is affected by several input variables and the objective is to optimize this response $[15,16]$. Through using the design of experiments (DOE) and applying regression analysis, the modeling of the desiring response with relation to the independent input variables can be gained. Consequentially, the RSM is utilized to describe and identify, with a great accuracy, the influence of the interactions of different independent variables on the response when they are varied simultaneously. In addition, RSM is one of the most widely used methods to solve the optimization problem in the manufacturing tasks [17-18]. Moreover, the optimal combination levels of machining parameters and the feasible prediction models were established. As a sophisticated process with high efficiency and high quality of surface integrity was achieved, the advanced materials shaped by the developed process of EDM in gas with practical and convenient features would be developed to fit the modern industrial requirements.

\section{Methods}

\subsection{Experimental Materials}

In the experimental work SKD 61 steel was adopted as the workpiece material, which dimension was $10 \mathrm{~mm} \times 10 \mathrm{~mm} \times$ $10 \mathrm{~mm}$. Moreover, the workpiece surface was ground firstly to guarantee the initial surface quality and parallelism before each experiment. The electrode material adopted cylindrical electrolytic copper with a through hole in the center. The outer and inner diameters of the electrode are $8 \mathrm{~mm}$ and 5 $\mathrm{mm}$, as well as $50 \mathrm{~mm}$ length, respectively. The end face of electrode against workpiece was ground by the emery papers on a granite surface plate in the sequence of mesh number $600 \#$, 800\#, and 1200\#. Therefore, the electrode surface roughness and parallelism were maintained at an identical situation. The dielectric media were adopted with compressed air that was dehumidified before passing to the machining gap between workpiece and tool electrode by a self-designed delivering system. The compressed air was regulated by a precision pressure valve to keep suppling the gas media to the machining gap at the desired setting conditions for each experiment.

\subsection{Experimental Equipment and Procedures}

In this investigation, a die-sinking EDM machine with transistor controlled circuit used as the experimental setup was a commercial type die-sinking EDM (Model 430C
CHMER Corp., Taiwan). A self-designed compressed air delivering system incorporated with metering instrument was employed to conduct a series of experiments in this work. The schematic diagram of the whole experimental setup is shown in Fig. 1. The compressed air was dehumidified first and adjusted by a regulated pressure vale to fit the requirement of experimental conditions. The compressed air, which delivered through central hole of electrode to the machining gap, served as the dielectric media in the EDM process. Consequently, the consecutive electrical sparks were generated and EDM progress was maintained. The melting and vaporizing material caused by EDM was ejected as fast as possible by high compressed air dielectric. Fig. 2 demonstrates the action of high pressure air within the machining gap during the EDM process.

The machining characteristics such as material removal rate (MRR, $\mathrm{mm}^{3} / \mathrm{min}$ ) and surface roughness $(\mathrm{Ra} / \mu \mathrm{m})$ were chosen to evaluate the effects of machining parameters on machining performances of the EDM in gas. The workpiece and electrode specimens were weighed by using an electronic balance (Percisa XT 220A) with $0.1 \mathrm{mg}$ resolution before and after each experiment to calculate MRR. Surface roughness was measured by a precision profilometer (Mitutoyo SJ 401) to assess the surface quality of the machined surface. The value of surface roughness was obtained by averaging five measurements that were stochastically conducted at different positions of the machined surface for each machining condition.

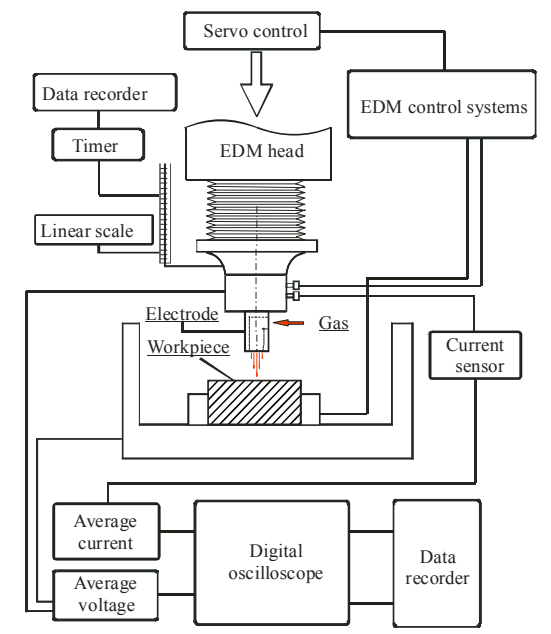

Figure 1. Schematic diagram of the experimental setup.

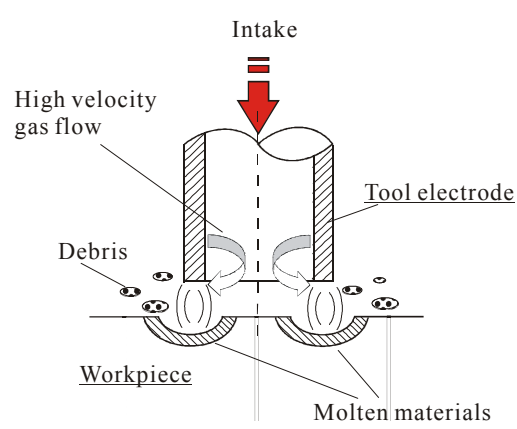

Figure 2. Demonstration of the action of high pressure gas within the machining gap. 


\subsection{Experimental Conditions}

The main machining parameters including peak current $\left(I_{p}\right)$, pulse duration $\left(T_{p}\right)$, gas pressure $\left(G_{p}\right)$, servo reference voltage $\left(S_{v}\right)$ were varied to determine their effects on machining performances such as MRR and SR with regard to EDM in gas. The observed responses and input parameters are listed in Table 1.

In this study, the experimental plans were designed on the basis of the central composite design (CCD) technique. The factorial portion of $\mathrm{CCD}$ is a full factorial design with all combinations of the factors at two level (high, +1 and low, -1) and composed of the eight star points, and six central points (coded level 0), which is the midpoint between the high and low levels. The star points are at the face of the cube portion on the design that corresponds to an $\alpha$ value of 1 , and this type of design is commonly called the "faced-centered CCD". In the present investigation, the experimental plans were conducted using the stipulated conditions according to the faced-centered $\mathrm{CCD}$ and involved 30 experimental observations at four independent input parameters. Each combination of experiment was carried out three times under the same conditions at different times to acquire a more accurate result in the EDM process. The machining time was set at 30 mins. The details of machining conditions conducted in this investigation are given in Table 2.

Table 1. The observed responses and input parameters.

\begin{tabular}{llllll}
\hline \multirow{2}{*}{ Response } & \multirow{2}{*}{ Parameters } & \multirow{2}{*}{ Unit } & \multicolumn{2}{c}{ Levels } & \\
\cline { 4 - 6 } & & & $\mathbf{- 1}$ & $\mathbf{0}$ & $\mathbf{+ 1}$ \\
\hline \multirow{2}{*}{$\mathrm{MRR}$} & $\mathrm{I}_{\mathrm{p}}$ & $\mathrm{A}$ & 5 & 10 & 15 \\
\multirow{3}{*}{$\mathrm{SR}$} & $\mathrm{T}_{\mathrm{p}}$ & $\mu \mathrm{s}$ & 250 & 500 & 750 \\
& $\mathrm{G}_{\mathrm{p}}$ & $\mathrm{Kg} / \mathrm{cm}^{2}$ & 1 & 3 & 5 \\
& $\mathrm{~S}_{\mathrm{v}}$ & $\mathrm{V}$ & 30 & 40 & 50 \\
\hline
\end{tabular}

Table 2. The details of machining conditions, observed responses and input parameters.

\begin{tabular}{lllllllllll}
\hline \multirow{2}{*}{ No. } & \multicolumn{1}{l}{ Code } & \multicolumn{1}{c}{ Parameters } & \multicolumn{3}{c}{ Responses } \\
\cline { 2 - 10 } & $\mathbf{X}_{\mathbf{1}}$ & $\mathbf{X}_{\mathbf{2}}$ & $\mathbf{X}_{\mathbf{3}}$ & $\mathbf{X}_{\mathbf{4}}$ & $\mathbf{I}_{\mathbf{p}}$ & $\mathbf{T}_{\mathbf{p}}$ & $\mathbf{G}_{\mathbf{p}}$ & $\mathbf{S}_{\mathbf{v}}$ & MRR & $\mathbf{S R}$ \\
\hline 1 & -1 & -1 & 1 & -1 & 5 & 250 & 5 & 30 & 0.102 & 1.42 \\
2 & -1 & -1 & 1 & 1 & 5 & 250 & 5 & 50 & 0.111 & 1.54 \\
3 & -1 & 1 & -1 & 1 & 5 & 750 & 1 & 50 & 0.097 & 1.48 \\
4 & -1 & 0 & 0 & 0 & 5 & 500 & 3 & 40 & 0.166 & 1.42 \\
5 & 1 & 1 & -1 & 1 & 15 & 750 & 1 & 50 & 0.441 & 2.14 \\
6 & 0 & 0 & 0 & 0 & 10 & 500 & 3 & 40 & 0.907 & 1.90 \\
7 & 1 & 0 & 0 & 0 & 15 & 500 & 3 & 40 & 1.404 & 2.31 \\
8 & 1 & 1 & -1 & -1 & 15 & 750 & 1 & 30 & 0.332 & 2.12 \\
9 & -1 & -1 & -1 & 1 & 5 & 250 & 1 & 50 & 0.086 & 1.40 \\
10 & -1 & 1 & 1 & 1 & 5 & 750 & 5 & 50 & 0.116 & 1.60 \\
11 & 1 & -1 & 1 & -1 & 15 & 250 & 5 & 30 & 2.192 & 2.75 \\
12 & 1 & -1 & 1 & 1 & 15 & 250 & 5 & 50 & 2.300 & 2.90 \\
13 & 0 & 1 & 0 & 0 & 10 & 750 & 3 & 40 & 1.018 & 2.02 \\
14 & 0 & -1 & 0 & 0 & 10 & 250 & 3 & 40 & 0.935 & 1.85 \\
15 & 0 & 0 & 1 & 0 & 10 & 500 & 5 & 40 & 1.262 & $2 . .05$ \\
16 & 1 & 1 & 1 & 1 & 15 & 750 & 5 & 50 & 2.446 & 2.99 \\
17 & 0 & 0 & 0 & 0 & 10 & 500 & 3 & 40 & 0.901 & 1.90 \\
18 & 0 & 0 & -1 & 0 & 10 & 500 & 1 & 40 & 0.282 & 1.57 \\
19 & 0 & 0 & 0 & 0 & 10 & 500 & 3 & 40 & 0.905 & 1.90 \\
20 & 1 & 1 & 1 & -1 & 15 & 750 & 3 & 30 & 2.311 & 2.78 \\
\hline & & & & & & & & & & \\
\hline
\end{tabular}

\begin{tabular}{lllllllllll}
\hline \multirow{2}{*}{ No. } & \multicolumn{1}{l}{ Code } & \multicolumn{9}{l}{ Parameters } \\
\cline { 2 - 11 } & $\mathbf{X}_{\mathbf{1}}$ & $\mathbf{X}_{\mathbf{2}}$ & $\mathbf{X}_{\mathbf{3}}$ & $\mathbf{X}_{\mathbf{4}}$ & $\mathbf{I}_{\mathbf{p}}$ & $\mathbf{T}_{\mathbf{p}}$ & $\mathbf{G}_{\mathbf{p}}$ & $\mathbf{S}_{\mathbf{v}}$ & MRR & $\mathbf{S R}$ \\
\hline 21 & 1 & -1 & -1 & 1 & 15 & 250 & 1 & 30 & 0.321 & 1.98 \\
22 & -1 & 1 & 1 & -1 & 5 & 750 & 3 & 30 & 0.108 & 1.52 \\
23 & -1 & 1 & -1 & -1 & 5 & 750 & 1 & 30 & 0.098 & 1.46 \\
24 & 0 & 0 & 0 & 1 & 10 & 500 & 3 & 50 & 0.921 & 2.16 \\
25 & 0 & 0 & 0 & 0 & 10 & 500 & 3 & 40 & 0.908 & 1.90 \\
26 & 0 & 0 & 0 & 0 & 10 & 500 & 3 & 40 & 0.911 & 1.90 \\
27 & 1 & -1 & -1 & -1 & 15 & 250 & 1 & 30 & 0.201 & 1.96 \\
28 & 0 & 0 & 0 & -1 & 10 & 500 & 3 & 30 & 0.865 & 1.98 \\
29 & 0 & 0 & 0 & 0 & 10 & 500 & 3 & 40 & 0.902 & 1.90 \\
30 & -1 & -1 & -1 & -1 & 5 & 250 & 1 & 30 & 0.087 & 1.30 \\
\hline
\end{tabular}

\subsection{Response Surface Methodology}

The RSM is an empirical modeling approach for determining the relationship between various process parameters and responses (machining performances) with the various desired criteria, and searching for the significance of these machining parameters on the coupled response. It is a sequential experimentation strategy for building and optimizing the empirical model. Therefore, RSM is a collection of mathematical and statistical procedures that are useful for the modeling and analysis of problems in which response of demand is affected by several variables and the objective is to optimize this response. By using experiments and applying regression analysis, the modeling of the desired response to several independent input variables can be obtained. Consequently, the RSM is utilized to accurately describe and identify the influence of the interactions of different independent variables on the response when they are varied simultaneously. In addition, it is one of the most widely used methods to solve the optimization problem in the manufacturing environment.

\subsection{Polynomial Model}

The RSM was employed for modeling and analysis of machining parameters a process (EDM in gas) in order to obtain the relationship to the machining performances (MRR, $\mathrm{SR}$ ). In the RSM, the quantitative form of relationship between desired response and independent input machining parameters can be represented as follows:

$$
Y=a_{0}+\sum_{i=0}^{n} a_{i} X_{i}+\sum_{i=1}^{n} a_{i i} X_{i}^{2}+\sum_{i<j}^{n} a_{i j} X_{i} X_{j}
$$

Where $Y$ is the measured responses, $X_{i}$ and $X_{j}$ are the independent variables, $a_{0}$ stands for the mean value of responses and $a_{i}, a_{i i}$ and $a_{i j}$ are linear, quadratic and interaction constant coefficients, correspondingly. The approximation of $Y$ was proposed using the fitted second order polynomial regression model which is called as quadratic model. The objective of using RSM is not only to investigate the response over the entire factor space, but also to locate the region of interest where the response reaches its optimum or near optimal value. By studying carefully the response surface model, the combination of factors, which gives the best response, can then be established. 


\section{Results and Discussion}

\subsection{Materials Removal Rate}

The mathematical model with regard to MRR obtained from the RSM technique was listed in the following (Eq.1). Moreover, the entire regression coefficients were demonstrated in the Table 3 , and the coefficients of the process in Eq. 2 were computed by software MINITAB 16.

$Y_{1}=0.906+0.61 X_{1}+0.035 X_{2}+0.5 X_{3}+0.03 X_{4}-0.121 X_{1}^{2}-0.071 X_{2}^{2}-$ $0.134 X_{3}^{2}-0.013 X_{4}^{2}+0.03 X_{1} X_{2}+0.493 X_{1} X_{3}+0.029 X_{1} X_{4}$

Table 3. The regression coefficients of MRR mathematical model.

\begin{tabular}{lll}
\hline Terms & Coefficients & $\mathbf{p}$ \\
\hline Constant & 0.905693 & 0.000 \\
$\mathrm{X}_{1}$ & 0.609833 & 0.000 \\
$\mathrm{X}_{2}$ & 0.035111 & 0.000 \\
$\mathrm{X}_{3}$ & 0.500167 & 0.000 \\
$\mathrm{X}_{4}$ & 0.030167 & 0.000 \\
$\mathrm{X}_{1} * \mathrm{X}_{1}$ & -0.120719 & 0.000 \\
$\mathrm{X}_{2} \mathrm{X}_{2}$ & 0.070781 & 0.000 \\
$\mathrm{X}_{3} * \mathrm{X}_{3}$ & -0.133719 & 0.000 \\
$\mathrm{X}_{4} * \mathrm{X}_{4}$ & -0.012719 & 0.015 \\
$\mathrm{X}_{1} * \mathrm{X}_{2}$ & 0.030187 & 0.000 \\
$\mathrm{X}_{1} * \mathrm{X}_{3}$ & 0.492813 & 0.000 \\
$\mathrm{X}_{1} * \mathrm{X}_{4}$ & 0.028562 & 0.000 \\
$\mathrm{X}_{2} * \mathrm{X}_{3}$ & 0.000187 & 0.921 \\
$\mathrm{X}_{2} * \mathrm{X}_{4}$ & 0.000938 & 0.622 \\
$\mathrm{X}_{3} * \mathrm{X}_{4}$ & 0.002062 & 0.286 \\
$\mathrm{R}-\mathrm{Sq}=97.82 \%$ & & \\
$\mathrm{R}-\mathrm{Sq}($ Adj. $=96.22 \%$ & & \\
\hline
\end{tabular}

Table 4. ANOVA of MRR model.

\begin{tabular}{lllllll}
\hline Source & DF & SS & Adj SS & MS & F & p \\
\hline Model & 14 & 15.425 & 14.962 & 1.10179 & 19800 & 0.000 \\
Residual & 15 & 0.0001 & 0.00001 & 0.00006 & & \\
Lack of fit & 10 & 0.0001 & 0.00001 & 0.00001 & 5.35 & 0.039 \\
Pure error & 5 & 0.0001 & 0.0001 & 0.0001 & & \\
Cor. total & 29 & 15.426 & & & & \\
\hline
\end{tabular}

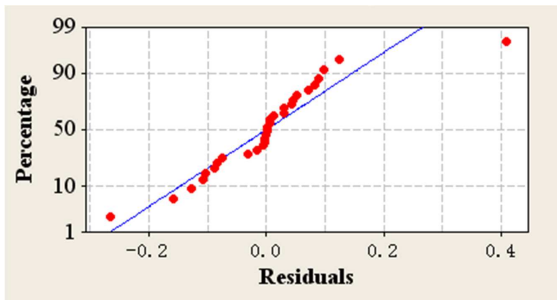

Figure 3. Normal probability plot of residuals for MRR.

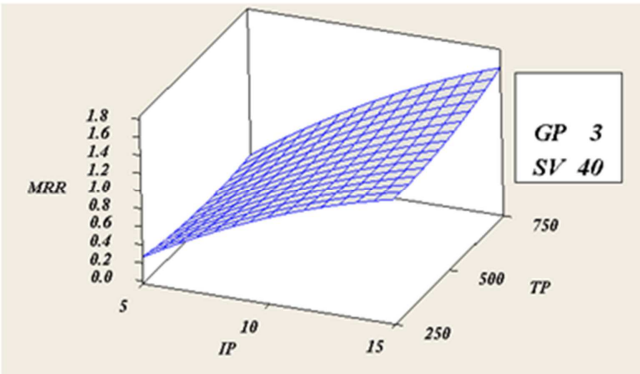

Figure 4. The response surface of MRR with regard to peak current $\left(I_{p}\right)$ and pulse duration $\left(T_{p}\right)$.

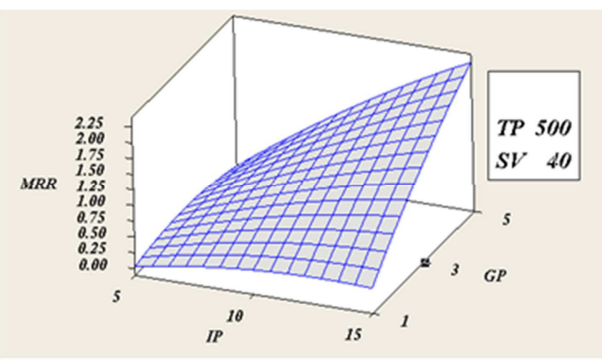

Figure 5. The response surface of $M R R$ with regard to peak current $\left(I_{p}\right)$ and Gas pressure $\left(G_{p}\right)$.

Tables 3 and 4 shows that the significant terms $(\mathrm{p}<0.05)$ in linear were peak current $\left(X_{1}\right)$, pulse duration $\left(X_{2}\right)$, gas pressure $\left(X_{3}\right)$, servo reference voltage $\left(X_{4}\right)$, and terms in square were also the same terms: peak current $\left(X_{l}\right)$, pulse duration $\left(X_{2}\right)$, gas pressure $\left(X_{3}\right)$, servo reference voltage $\left(X_{4}\right)$. The interaction terms were $\left(X_{1} \times X_{2}\right)$ peak current and pulse duration, $\left(X_{1} \times X_{3}\right)$ peak current and gas pressure, $\left(X_{1} \times X_{4}\right)$ peak current and servo reference voltage. The $\mathrm{R}^{2}$ was $97.87 \%$ and adjustment $\mathrm{R}^{2}$ was $96.22 \%$. Moreover, the data fall on a straight line indicating that errors are distributed normally (see Fig. 3). It was observed that majority of the data were close to the straight line. Hence, it can be inferred that the plots yield better results for future prediction.

The prediction performance of MRR could be obtained from the established model. Fig. 4 shows the MRR of peak current increased from $5 \mathrm{~A}$ to $15 \mathrm{~A}$ and the pulse duration extended from $250 \mu \mathrm{s}$ to $750 \mu \mathrm{s}$, when the gas pressure set at $3 \mathrm{~kg} / \mathrm{cm}^{2}$ and servo reference voltage fixed at $40 \mathrm{~V}$. The prediction results illustrate that MRR increased with the peak current and pulse duration. Fig. 5 shows the MRR of peak current increased from $5 \mathrm{~A}$ to $15 \mathrm{~A}$ and gas pressure enhanced from $1 \mathrm{~kg} / \mathrm{cm}^{2}$ to $5 \mathrm{~kg} / \mathrm{cm}^{2}$ when the pulse duration set at $500 \mu \mathrm{s}$ and the servo reference voltage fixed at $40 \mathrm{~V}$. The MRR enlarged with the increase of peak current and gas pressure. The effects of peak current and reference voltage on MRR are depicted on Fig. 7. The peak current enlarged from $5 \mathrm{~A}$ to $15 \mathrm{~A}$ and the reference voltage extended from $30 \mathrm{~V}$ to $50 \mathrm{~V}$, the MRR increased with increase of the peak current and the reference voltage when pulse duration fixed at $500 \mu \mathrm{s}$ and gas pressure set at $3 \mathrm{~kg} / \mathrm{cm}^{2}$.

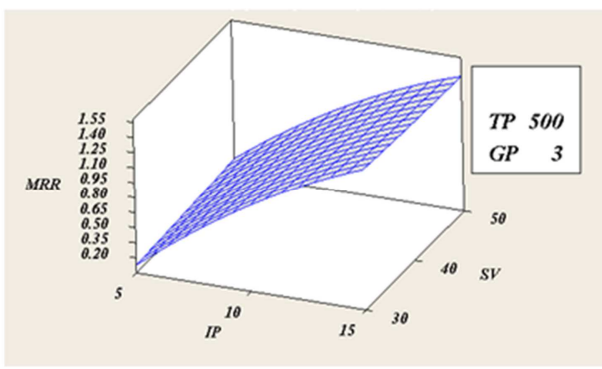

Figure 6. The response surface of MRR with regard to peak current $\left(I_{p}\right)$ and servo reference voltage $\left(S_{v}\right)$.

\subsection{Surface Roughness}

The mathematical model with relation to SR obtained from 
the RSM technique was listed in the following (eq.3). Moreover, the entire regression coefficients were demonstrated in the Table 5.

$$
\begin{gathered}
Y_{2}=1.902+0.499 X_{1}+0.052 X_{2}+0.232 X_{3}+0.051 X_{4}-0.098 X_{1}^{2}+ \\
0.166 X_{4}^{2}+0.186 X_{1} X_{3}
\end{gathered}
$$

Tables 5 and 6 shows that the significant terms $(\mathrm{p}<0.05)$ in linear were peak current $\left(X_{1}\right)$, pulse duration $\left(X_{2}\right)$, gas pressure $\left(X_{3}\right)$, servo reference voltage $\left(X_{4}\right)$, and in square terms were gas pressure $\left(X_{3}\right)$ and servo reference voltage $\left(X_{4}\right)$. The interaction term was $\left(X_{1} \times X_{3}\right)$ peak current. The $\mathrm{R}^{2}$ was $97.29 \%$ and adjustment $\mathrm{R}^{2}$ was $96.22 \%$. Moreover, the experimental data fall on a straight line revealing that the errors are distributed normally (see Fig. 7), and indicated that the plots yield better results for prediction model.

Fig. 8 shows the relationship of peak current and the pulse duration on SR. The gas pressure set at $3 \mathrm{~kg} / \mathrm{cm}^{2}$ and servo reference voltage fixed at $40 \mathrm{~V}$. The prediction results of SR illustrate a trend that the SR increased with the peak current and pulse duration. Fig.9 depicts the SR of peak current raised from $5 \mathrm{~A}$ to $15 \mathrm{~A}$ and gas pressure enlarged from 1 $\mathrm{kg} / \mathrm{cm}^{2}$ to $5 \mathrm{~kg} / \mathrm{cm}^{2}$ as the pulse duration set at $500 \mu \mathrm{s}$ and the servo reference voltage fixed at $40 \mathrm{~V}$. The prediction values of SR shows a perspective that the SR amplified with the increase of peak current and gas pressure. The effects of peak current and reference voltage on SR are depicted on Fig. 10. The peak current enlarged from $5 \mathrm{~A}$ to $15 \mathrm{~A}$ and the reference voltage extended from $30 \mathrm{~V}$ to $50 \mathrm{~V}$, the SR augmented with the increase of peak current and servo reference voltage as fixed pulse duration at $500 \mu \mathrm{s}$ and gas pressure at $3 \mathrm{~kg} / \mathrm{cm}^{2}$.

Table 5. The regression coefficient of SR mathematical model.

\begin{tabular}{lll}
\hline Terms & Coefficients & p \\
\hline Constant & 1.90218 & 0.000 \\
$\mathrm{X}_{1}$ & 0.49878 & 0.000 \\
$\mathrm{X}_{2}$ & 0.05211 & 0.001 \\
$\mathrm{X}_{3}$ & 0.23167 & 0.000 \\
$\mathrm{X}_{4}$ & 0.05078 & 0.001 \\
$\mathrm{X}_{1} * \mathrm{X}_{1}$ & -0.03935 & 0.263 \\
$\mathrm{X}_{2} * \mathrm{X}_{2}$ & 0.03065 & 0.380 \\
$\mathrm{X}_{3} * \mathrm{X}_{3}$ & -0.09835 & 0.011 \\
$\mathrm{X}_{4} * \mathrm{X}_{4}$ & 0.16565 & 0.000 \\
$\mathrm{X}_{1} * \mathrm{X}_{2}$ & 0.00800 & 0.566 \\
$\mathrm{X}_{1} * \mathrm{X}_{3}$ & 0.18550 & 0.000 \\
$\mathrm{X}_{1} * \mathrm{X}_{4}$ & 0.01587 & 0.262 \\
$\mathrm{X}_{2} * \mathrm{X}_{3}$ & -0.02200 & 0.127 \\
$\mathrm{X}_{2} * \mathrm{X}_{4}$ & 0.00338 & 0.808 \\
$\mathrm{X}_{3} * \mathrm{X}_{4}$ & 0.02587 & 0.077 \\
$\mathrm{R}-\mathrm{Sq}=97.29 \%$ & & \\
$\mathrm{R}-\mathrm{Sq}($ Adj. $)=96.22 \%$ & & \\
\hline
\end{tabular}

Table 6. ANOVA of SR model.

\begin{tabular}{lllllll}
\hline Source & DF & SS & Adj SS & MS & F & p \\
\hline Model & 14 & 6.21068 & 6.02435 & 0.44362 & 149.24 & 0.000 \\
Residual & 15 & 0.04459 & 0.04325 & 0.00297 & & \\
Lack of fit & 10 & 0.04459 & 0.04432 & 0.00446 & & \\
Pure error & 5 & 0.00000 & 0.00000 & 0.00000 & & \\
Cor. total & 29 & 6.25527 & & & & \\
\hline
\end{tabular}

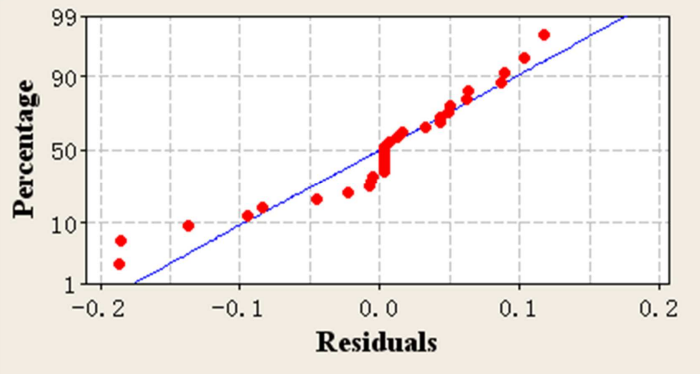

Figure 7. Normal probability plot of residuals for MRR.

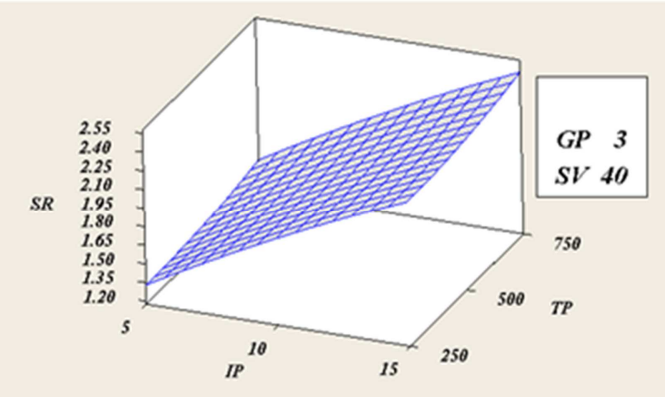

Figure 8. The response surface of $S R$ with regard to peak current $\left(I_{p}\right)$ and pulse duration $\left(T_{p}\right)$.

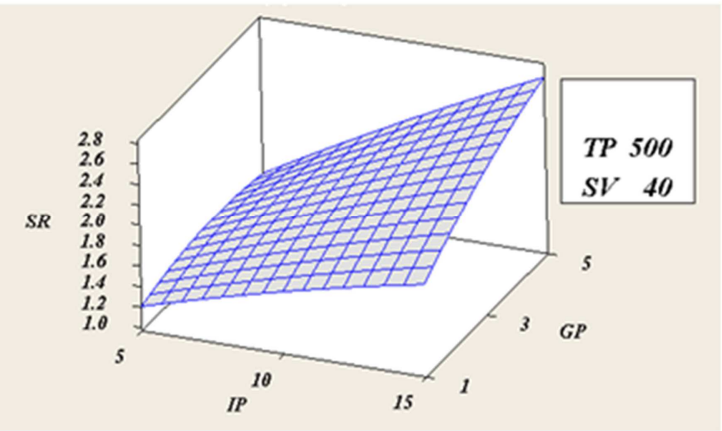

Figure 9. The response surface of $S R$ with regard to peak current $\left(I_{p}\right)$ and gas pressure $\left(G_{p}\right)$

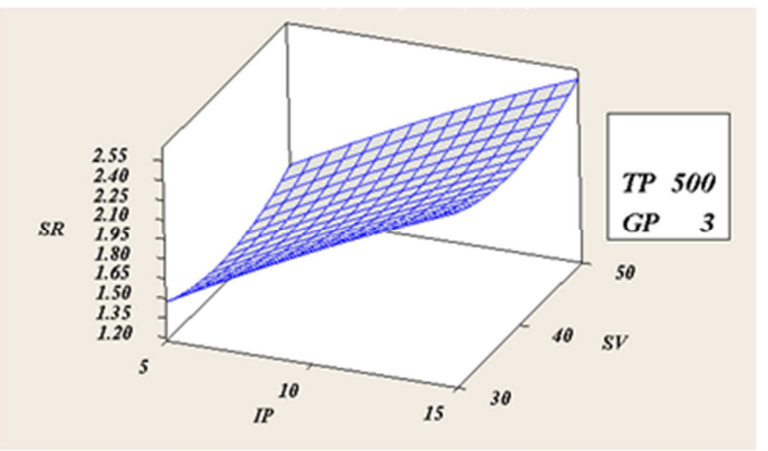

Figure 10. The response surface of $S R$ with regard to peak current $\left(I_{p}\right)$ and servo reference voltage $\left(S_{v}\right)$.

Table 7. The optimal combination levels of machining parameters.

\begin{tabular}{lllll}
\hline Parameters & Code & Symbol & Setting & Unit \\
\hline $\mathrm{X}_{1}$ & 0.4747 & $\mathrm{I}_{\mathrm{p}}$ & 12 & $\mathrm{~A}$ \\
$\mathrm{X}_{2}$ & 1 & $\mathrm{~T}_{\mathrm{p}}$ & 750 & $\mu \mathrm{s}$ \\
$\mathrm{X}_{3}$ & 1 & $\mathrm{G}_{\mathrm{p}}$ & 5 & $\mathrm{Kg} / \mathrm{cm}^{2}$ \\
$\mathrm{X}_{4}$ & -0.7172 & $\mathrm{~S}_{\mathrm{v}}$ & 34 & $\mathrm{~V}$ \\
\hline
\end{tabular}


Table 8. Confirmation tests.

\begin{tabular}{llllllll}
\hline \multirow{2}{*}{ No. } & \multicolumn{2}{l}{ MRR } & \multicolumn{7}{l}{ } & $\mathbf{X}_{\mathbf{1}}$ & $\mathbf{X}_{\mathbf{2}}$ & $\mathbf{X}_{\mathbf{3}}$ & $\mathbf{X}_{\mathbf{4}}$ & Experiment & Prediction & Error \\
\hline 1 & 5 & 250 & 1 & 30 & 0.090 & 0.087 & $4 \%$ \\
2 & 10 & 500 & 3 & 40 & 0.901 & 0.900 & $0 \%$ \\
3 & 15 & 750 & 5 & 50 & 2.45 & 2.446 & $3 \%$ \\
4 & 12 & 750 & 5 & 34 & 1.79 & 1.85 & $3 \%$ \\
& SR & & & & & & \\
1 & 5 & 250 & 1 & 30 & 1.30 & 1.37 & $5 \%$ \\
2 & 10 & 500 & 3 & 40 & 1.90 & 1.90 & $0 \%$ \\
3 & 15 & 750 & 5 & 50 & 3.154 & 2.985 & $5 \%$ \\
4 & 12 & 750 & 5 & 34 & 2.48 & 2.56 & $3 \%$ \\
\hline
\end{tabular}

\subsection{Optimal Analysis and Confirmation Test}

The optimal parameter setting levels could be derived from the established mathematic model. The optimal combination levels of the machining parameters and the desired machining performances could be obtained from MINITAB 16. The analysis results lists in Table 7. The optimal levels of the machining variables were peak current $12 \mathrm{~A}$, pulse duration $750 \mu \mathrm{s}$, gas pressure $5 \mathrm{Kg} / \mathrm{cm}^{2}$, and servo reference voltage $34 \mathrm{~V}$. Moreover, the MRR was $1.9 \mathrm{~mm}^{3}$ and the SR was $2.43 \mu \mathrm{m}(\mathrm{Ra})$ at the optimal combination levels of the machining parameters. The desired performances were confirmed with the experimental results, and the analysis desired values were conformed to the experimental data. It is seen in Table 8 . The errors were less than $5 \%$. Thus, the analysis desired values were acceptable. Therefore, the regression models were significant in explaining the relationship between respective responses (MRR and SR) and input machining parameters.

\section{Conclusion}

This investigation explored the effects of EDM in gas on MRR and SR with relation to the machining parameters in processing SKD 61 tool steel based on the RSM approach. The conclusions could be drawn from the experimental results and analyses.

(1) The mathematical model of second order polynomial was established with relation to the main machining parameters such as peak current $\left(X_{1}\right)$, pulse duration $\left(X_{2}\right)$, gas pressure $\left(X_{3}\right)$, and servo voltage $\left(X_{4}\right)$, as well as the prediction values revealed well agreement with the experimental data.

(2) The significant terms for MRR in linear were peak current, pulse duration, gas pressure, and servo reference voltage, as well as terms in square were peak current, pulse duration, gas pressure, and servo reference voltage. Moreover, the significant terms with interaction were peak current and pulse duration, peak current and gas pressure, peak current and servo reference voltage drawn from the developed mathematical model.

(3) The significant terms for SR in linear were peak current, pulse duration, gas pressure, and servo reference voltage, as well as terms in square were gas pressure, and servo reference voltage. Moreover, the significant term with interaction was peak current and gas pressure resulted from the developed mathematical model.

(4) The parameter settings for peak current $\left(X_{1}\right) 0.4747$, pulse duration $\left(X_{2}\right) 1$, gas pressure $\left(X_{3}\right) 1$, and servo reference voltage $\left(X_{4}\right)-0.7172$ could obtain the optimal values of MRR $1.99 \mathrm{~mm}^{3}$ and SR $2.43 \mu \mathrm{m}$ from the analysis of RSM.

\section{Acknowledgements}

The authors would like to thank the Ministry of Science and Technology of the Republic of China, Taiwan, for financially supporting this research under Contract No. NSC 102-2221-E-252-002-MY3.

\section{References}

[1] C. J. Luis, I. Puertas, G. Villa, "Material removal rate and electrode wear study on the EDM of silicon carbide," J. Mater. Process. Technol. Vol. 164-165, 2005, pp. 889-896.

[2] Y. C. Lin, Y. F. Chen, C. T. Lin, H. J. Tzeng, "Electrical discharge machining (EDM) characteristics associated with electrical discharge energy on machining of cemented tungsten carbide," Mater. Manuf. Process. Vol. 23, 2008, pp. 391-399.

[3] C. H. C. Harron, B. M. Deros, A. Ginting and M. Fauziah, "Investigation on the influence of machining parameters when machining tool steel using EDM," J. Mater. Process. Technol. Vol.116, 2001, pp. 84-87.

[4] I. Puertas, C. J. Luis, "A study of optimization of machining parameters for electrical discharge machining of boron carbide," Mater. Manuf. Process. Vol. 19(6), 2004, pp. 1041-1070.

[5] Y. C. Lin, C. H. Cheng, P. L. Su, L. R. Hwang, "Machining characteristics and optimization of machining parameters of SKH 57 HSS using EDM based on Taguchi method," Mater. Manuf. Process. Vol. 21, 2006, pp. 922-929.

[6] M. Kiyak, O. Cakir, "Examination of machining parameters on surface roughness in EDM of tool steel," J. Mater. Process. Technol. Vol.191, 2007, pp. 141-144.

[7] M. Kunieda, M. Yoshida, "Electrical discharge machining in Gas,” Ann. CIRP, Vol. 46(1), 1997, pp. 143-146.

[8] M. Kunieda, T. Takaya, S. Nakano, "Improvement of dry EDM characteristics using piezoelectric actuator," Ann. CIRP Vol. 53(1), 2004, pp. 183-186.

[9] Y. J. Lin, Y. C. Lin, A. C. Wang, Y. F. Chen, H. M. Chow, "Machining characteristics of EDM using gas media," Adv. Mater. Res. Vol.189-193, 2011, pp.3132-3130.

[10] M. Kuneida, C. Furudate, High precision finish cutting by dry WEDM, Ann. CIRP, 50(1) (2001) 121-124.

[11] T. Wang, M. Kunieda, "Study on dry WEDMed surface layer of cold tool steel SKD 11," Int. J. Electr. Mach. Vol. 7, 2002, pp. 3-4.

[12] Z. Yu, T. Jun, K. Masanori, "Dry electrical discharge machining of cemented carbide," J. Mater. Process. Technol. Vol.149, 2004, pp. 353-357.

[13] S. S. Baraskar, S. S. Banwait, S. C. Laroiya, "Multi objective optimization of electrical discharge machining process using a hybrid method," Mater. Manuf. Process., Vol. 28, 2013, pp. 348-354. 
[14] B. Muralidharan, H. Chelladurai, "Experimental analysis of electro-discharge deposition process," Int. J. Adv. Manuf. Technol., Vol.76, 2015, pp.69-82.

[15] A. P. Tiwary, B. B. Pradhan, B. Bhattacharyya, "Study on influence of micro-EDM process parameters during machining of Ti-6Al-4V superalloy,” Int. J. Adv. Manuf. Technol., Vol. 76, 2015, pp. 151-160.
[16] V. Aggarwal, S. S. Khangura, R. K. Garg, "Parametric modeling and optimization for wire electrical discharge machining of Inconel 718 using response surface methodology," Int. J. Adv. Manuf. Technol., Vol. 79, 2015, pp. 31-47. 